\title{
Preface
}

On behalf of The First International Conference on Energy, Power, Petroleum and Petrochemical Engineering (E3PE2017), the program committees of the conference, Faculty of Engineering - Lebanese University, Beirut, Lebanon, have the pleasure to welcome the attendees to Faculty of Engineering Lebanese University, Beirut, Lebanon to participate in The First International Conference on Energy, Power, Petroleum and Petrochemical Engineering (E3PE2017) during the period of April 26-28, 2017. In this edition, E3PE2017 is providing a venue for high quality papers in a wide range of research areas in the energy, Power, Petroleum and Petrochemical Engineering fields. The conference has recorded the receipt of around 52 papers, out of which 18 were accepted forpublication, resulting an acceptance rate of $35 \%$. The accepted papers were authored by researchers from more than 10 countries. Each paper was evaluated by a minimum of two reviewers. Additional reviews were also conducted, if necessary. Authors received reviewers' comments to be considered in the final manuscript of their papers. We're distinctly pleased to have distinguished invited speakers. They will offer their lecturers over keynote presentation sessions. The parallel sessions cover the following topics: Renewable Energy, Petroleum and Petrochemical Engineering, Energy Management Systems Chemical Industry Technologies and Products, Enhanced Oil Recovery, Ecology and Environmental Technologie and many more related Petroleum and Petrochemical Engineering topics.

\section{General Chair}

Prof. Nazih Moubayed, Lebanese University, Lebanon 